\title{
Design and Fabrication of SOI-based photonic crystal components
}

Borel, Peter Ingo; Frandsen, Lars Hagedorn; Harpøth, Anders; Kristensen, M.; Niemi, Tapio; Xing, P.; Jensen, Jakob Søndergaard; Sigmund, Ole

Published in:

Procedings of 6th IEEE International Conference on Transparent Optical Networks ICTON 2004

Publication date:

2004

Document Version

Publisher's PDF, also known as Version of record

Link back to DTU Orbit

Citation (APA):

Borel, P. I., Frandsen, L. H., Harpøth, A., Kristensen, M., Niemi, T., Xing, P., Jensen, J. S., \& Sigmund, O. (2004). Design and Fabrication of SOl-based photonic crystal components. In Procedings of 6th IEEE International Conference on Transparent Optical Networks ICTON 2004 (Vol. 1, pp. 271-275). National Institute of Telecommunications.

\section{General rights}

Copyright and moral rights for the publications made accessible in the public portal are retained by the authors and/or other copyright owners and it is a condition of accessing publications that users recognise and abide by the legal requirements associated with these rights.

- Users may download and print one copy of any publication from the public portal for the purpose of private study or research.

- You may not further distribute the material or use it for any profit-making activity or commercial gain

- You may freely distribute the URL identifying the publication in the public portal 


\title{
Design and Fabrication of SOI-Based Photonic Crystal Components
}

\author{
Peter I. Borel, Lars H. Frandsen, Anders Harpøth, Martin Kristensen, Tapio Nemi, Pengfei Xing \\ Jakob S. Jensen*, Ole Sigmund* \\ Research Center COM, Building 345v, DTU, Kgs. Lyngby, DK-2800, Denmark \\ * Department of Mechanical Engineering, Building 404, DTU, Kgs. Lyngby, DK-2800, Denmark \\ Tel: (+45) 4525 3772,Fax: (+45) 512 8347, e-mail: pib@com.dtu.dk
}

\begin{abstract}
We present examples of ultra-compact photonic crystal components realized in silicon-on-insulator material. We have fabricated several different types of photonic crystal waveguide components displaying high transmission features. This includes $60^{\circ}$ and $120^{\circ}$ bends, different types of couplers, and splitters. Recently, we have designed and fabricated components with more than $200 \mathrm{~nm}$ bandwidths. Design strategies to enhance the performance include systematic variation of design parameters using finite-difference time-domain simulations and inverse design methods such as topology optimization.
\end{abstract}

\section{INTRODUCTION}

Planar photonic crystal $(\mathrm{PhC})$ structures are specially engineered dielectric materials with periodic modulation of the refractive index. The modulation is typically designed to forbid propagation of light in some wavelength ranges, so-called photonic bandgaps (PBGs) [1-3]. The PBG effect allows the interaction between light and the $\mathrm{PhC}$ structure to take place on a scale of the order of a wavelength and typical $\mathrm{PhC}$ features are of nano-scale size. Breaking the crystal symmetry by introducing line defects and other discontinuities allows control of the light on a sub-wavelength scale in the PhCs. These facts may be used to minimize the size of the individual PhC components and, thus, greatly increase the device packing density (up to $10^{5}-10^{6}$ times compared to conventional total-internal-reflection components).

The research in $\mathrm{PhC}$ waveguides has now matured to a level where present fabrication technologies allow the fabrication of waveguides with sufficient low loss properties [4-8]. Today, there is worldwide focus on the design and fabrication of $\mathrm{PhC}$ waveguide $(\mathrm{PhCW})$ structures having sufficient bandwidth and various userdefined functionalities. PhC structures with $20-40 \mathrm{~nm}$ useful optical bandwidths have previously been demonstrated [9-11]. Until now, however, no bandgap-based $\mathrm{PhC}$ components have been demonstrated with satisfactory performance in a broad wavelength range. A major reason for this has been the lack of efficient design tools. Therefore, PhC design structures today are often obtained either by intuition or by varying one or two design parameters in a more or less systematic way.

In this paper we present different design strategies on how to improve the performance of various $\mathrm{PhC}$ structures. It is discussed how systematic repeated 3D finite-difference time-domain (FDTD) calculations [12] may be utilized in the design phase to enhance the performance. Also, a presentation is given of the efficient inverse design strategy topology optimization [13], which allows creation of improved PhC components with previously unseen low transmission losses and/or high operational bandwidths.

The fabrication procedure of silicon-on-insulator (SOI) based $\mathrm{PhCW}$ structures utilizing either e-beam or 248-nm deep UV lithography is discussed. Furthermore, some examples of the performance of fabricated structures are given. We have fabricated several different types of $\mathrm{PhCW}$ components, which display low losses $[4,5]$. This includes $60^{\circ}, 90^{\circ}$ and $120^{\circ}$ bends $[4,5,13]$, different types of couplers [5,9], and $50 / 50$ splitters $[10]$.

\section{DESIGN OF PHCWs}

Design strategies to enhance the performance of $\mathrm{PhC}$ components include systematic variation of design parameters using repeated FDTD simulations [12] and inverse design methods such as topology optimization [13]. In the cases investigated here, the PhCWs are defined by removing one row of holes in a triangular array of air holes as indicated in Fig. 1. Thereby, light is confined horizontally by an in-plane PBG and vertically by total internal reflection. The bulk hole diameter, $D$, is typically chosen in the range $0.5 \Lambda-0.7 \Lambda$, where the lattice constant $\Lambda \approx 400-440 \mathrm{~nm}$. The material is SOI, consisting of a $220-300 \mathrm{~nm}$ layer of silicon on top of a $1-\mu \mathrm{m}$ layer of silica.

The work reported in this paper was supported in part by the European IST-PICCO project and the Danish Technical Research Council through the research programs 'Planar Integrated PBG Elements' and 'Designing bandgap materials and structures with optimized dynamic properties'. 


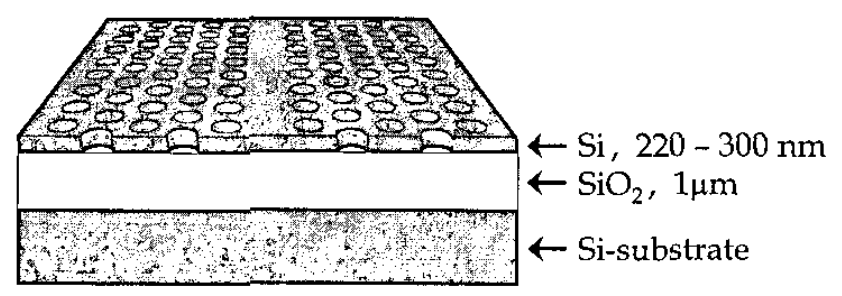

Figure 1. Sketch of the typical building block in the present work, a WI PhCW.

\subsection{Repeated FDTD calculations}

Due to the PBG effect in a PhCW component, light may be routed around sharp corners such as the one sketched in Fig. 2 (top left). However, in single mode operation, small discontinuities in the straight $\mathrm{PhCW}$ can introduce large reflections at the interface between different sections of the $\mathrm{PhCW}$. Discontinuities may also excite higher order modes, which are not necessarily guided in the PhCW. As a result, the $60^{\circ}$ bend shown in Fig. 2 (top left) only has a very narrow bandwidth region $(\sim 20 \mathrm{~nm})$ with reasonable high transmission. As the functionality of the $\mathrm{PhC}$ component arises from discontinuities, care is a necessity when designing PhCW components in order to avoid losses.
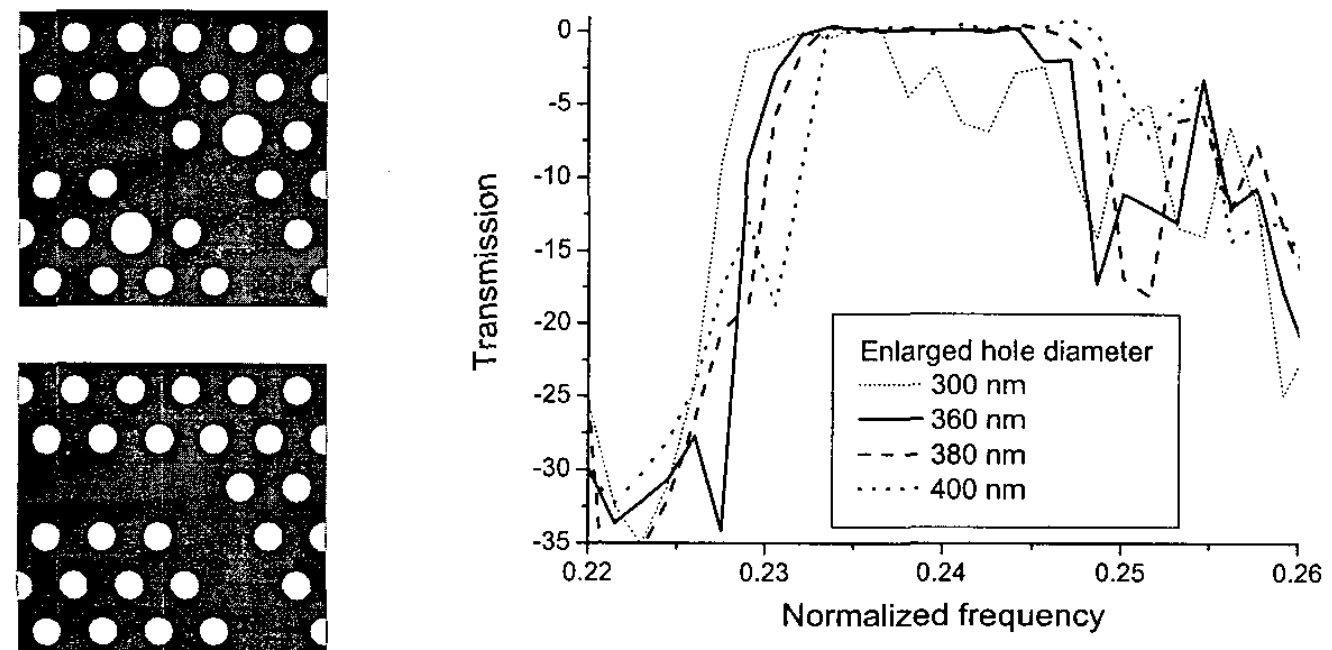

Figure 2. (Top left): Standard PhCW $60^{\circ}$ bend. (Bottom left): $P h C W 60^{\circ}$ bend where one hole is displaced and three holes are enlarged. (Right): Calculated transmission for different enlarged hole diameters.

To improve the bandwidth of sharp PhCW bends we first consider the type of $60^{\circ}$ bend shown in Fig. 2 (bottom left). Note that one hole is displaced and the diameter of three holes is enlarged. This design is based on intuition from microwave engineering. In order to determine the diameter of the enlarged holes that ensures the largest high-transmission bandwidth for this type of design, systematic repeated 3D FDTD simulations were carried out. In the calculations the regular holes had a diameter of $300 \mathrm{~nm}$ and the period was $\Lambda=420 \mathrm{~nm}$. The diameter of the large holes was varied from $300 \mathrm{~nm}$ to $400 \mathrm{~nm}$. Representative calculated transmission spectra for TE polarized light for different enlarged hole-diameters are shown in Fig. 2 (right). The calculated transmitted light intensity of the $\mathrm{PhCW}$ was normalized to the entrance light intensity. Further details of the FDTD calculations are reported in Ref. [12]. It is seen from the figure that a substantially enhanced bandwidth is obtained by choosing a large-hole diameter around $380 \mathrm{~nm}$. The experimental realization of a $60^{\circ}$ bend of this type is discussed in Section 4.

\subsection{Topology Optimization}

As observed in the above example systematic repeated FDTD calculations may lead to substantially improved designs. A considerable challenge when employing this method is, however, that for most optimization problems the parameter space is immense. Hence, to use this method with success a great deal of insight and intuition is often required by the designer when deciding which parameters to vary and which to keep fixed.

Recently, we have embarked on employing a unique inverse design method, topology optimization [13]. The method was originally developed for structural optimization problems $[14,15]$, and is today used with success to 
design bridges, cars, and airplanes. The method is based on repeated finite element analyses where the material distribution is modified iteratively in the given design area to improve the specified performance parameter. The obtained $\mathrm{PhC}$ designs are unrestrained from geometrical restrictions such as the size, shape, and number of holes. In our experimental and numerical work we have found that topology optimization allows creation of improved $\mathrm{PhC}$ components with previously unseen low transmission losses and high operational bandwidths [13]. As an example, the experimental performance of $\mathrm{PhCW} 120^{\circ}$ bends designed using topology optimization is presented in Section 4.

\section{FABRICATION OF SILICON-ON-INSULATOR BASED PhCWs}

The $\mathrm{PhC}$ structures were created in a $\mathrm{SiO}_{2} / \mathrm{Si} / \mathrm{SiO}_{2}$ trilayer film by arranging holes in a triangular array with lattice constant $\Lambda$. This configuration is known to give a large bandgap for TE polarized light [16]. The PhCWs were defined by removing single rows of holes in the otherwise perfect photonic crystal. Typical experimental $\mathrm{PhCW}$ and SOI-wafer parameters for the fabricated structures have already been given in Section 2 and shown in Fig. 1. Ridge waveguides, gradually tapered from a width of $4 \mu \mathrm{m}$ at the sample facet to $1 \mu \mathrm{m}$ at the PhCW interface, are used to couple light into and out of the PhCWs.

The hole patterns were defined in a resist spun on top of the SOI wafer either using e-beam lithography or deep UV lithography. Both lithographic methods can be used to fabricate PhCWs of high quality, and each method offers its own benefits. A major advantage of deep UV lithography is its inherent capability for mass fabrication of $\mathrm{PhCW}$ structures. A major advantage of e-beam lithography is that it allows fabrication of holes of special shapes and sizes even down to very small feature sizes.

The written patterns were transferred to the Si layer by reactive ion etching (RIE) utilizing the e-beam resist as a mask. In some cases the perforated top silicon layer was subsequently used as a mask in a RIE of silica to make the $\mathrm{PhC}$ pattern penetrate $\sim 100 \mathrm{~nm}$ down into the underlying silica layer. The reason for not letting the $\mathrm{PhC}$ holes penetrate deep into the silica layer is the low selectivity in the RIE between silicon and silica. Scanning electron micrographs of some of the fabricated samples are shown in next section.

The characterization setups used to measure the transmission spectra of the fabricated waveguides have been described in detail elsewhere $[5,13]$.

\section{EXPERIMENTAL RESULTS}

In this section various examples of the performance of fabricated $\mathrm{PhCW}$ structures are presented. The employed design strategies have either been systematic repeated 3D FDTD simulations or topology optimization.

Figure 3 (left) displays an experimental realization of the bend sketched in Fig. 2 (bottom left) fabricated using deep UV lithography [17]. The transmission spectrum for TE-polarized light for the bend is normalized to a straight PhCW of equivalent propagation length in order to obtain the bend loss. The measured spectra are compared to 3D FDTD calculations performed on $60^{\circ}$ bends and straight waveguides identical to the fabricated ones, and normalized the same way. The measured and calculated bend losses are displayed in Fig. 3 (right). Especially noteworthy is the $70 \mathrm{~nm}$ bandwidth with low bend loss: It is found to be $\sim 1 \mathrm{~dB}$ experimentally, and $\sim 0.5 \mathrm{~dB}$ theoretically in the wavelength range $1500-1570 \mathrm{~nm}$.
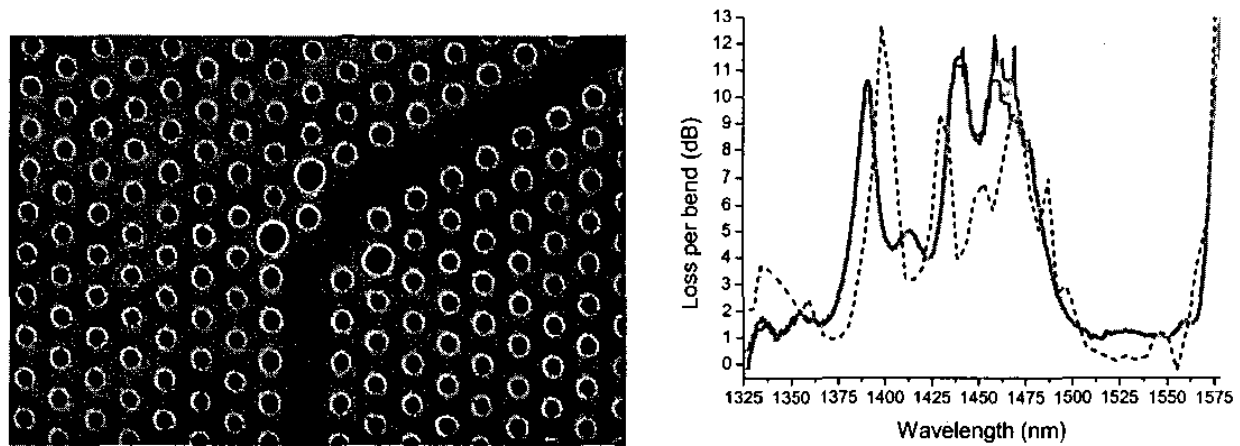

Figure 3. (Left) Scanning electron micrograph of the fabricated $60^{\circ}$ bend. The diameter of the large holes is $330 \mathrm{~nm}$. (Right) Measured (gray) and calculated (dashed black) bend loss for one $60^{\circ}$ bend.

The inverse design method topology optimization has been utilized to design two consecutive $\mathrm{PhCW} 120^{\circ}$ bends [13]. The resulting optimized Z-bend design as well as the experimental realization in a SOI PhC is displayed in Fig. 4 (left). The PhCW Z-bend has been fabricated using e-beam lithography. The measured and calculated bend losses for TE polarized light transmitted through the fabricated Z-bend are shown in Fig. 4 (right). As 
before the transmission spectra have been normalized to transmission spectra for straight PhCWs of same lengths.

The most prominent feature of the spectra is the exceptionally broad wavelength range of more than $200 \mathrm{~nm}$ having a low bend loss of just above $\sim 1 \mathrm{~dB}$. This is to the best of our knowledge by far the largest bandwidth with low bend loss demonstrated for the TE polarization in a $\mathrm{PhC}$ waveguide. Without topology optimization 3D FDTD calculations show up to $\sim 10 \mathrm{~dB}$ higher loss per bend.
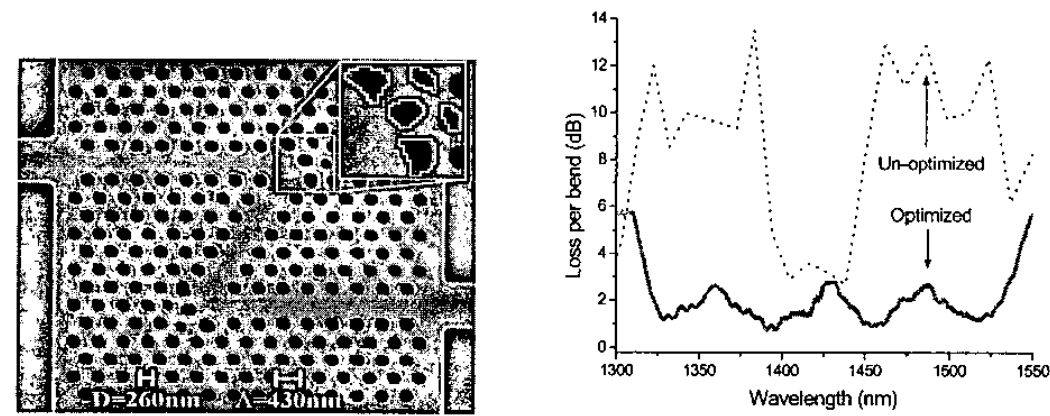

Figure 4. Scanning electron micrograph of the fabricated Z-bend. The number, shape and size of the holes at each bend are designed using topology optimization. The inset shows a magnified view of the optimized holes as designed (white contour) and actually fabricated. The measured (gray) and 3D FDTD calculated (solid black) loss per bend for TE polarized light in the fabricated structure. Also shown is the 3D FDTD calculated bend loss for the un-optimized (dotted black) Z-bend [12].

Other PhCWs components than bends have also been fabricated and investigated including the wavelength selective directional coupler $[5,9]$ and the $50 / 50 \mathrm{Y}$-splitter. The Y-splitter is a key optical component that is widely used in interferometers and (de)multiplexers. We have fabricated a PhCW Y-splitter using deep UV lithography for which we have obtained ultra-low-loss 3-dB splitting for TE-polarized light [10]. The fabricated $\mathrm{PhCW}$ Y-splitter is shown in Fig. 5 (left). Note that the $60^{\circ}$ bends utilized in this splitter are different from the ones discussed earlier. The measured and calculated transmission spectra for the Y-splitter are shown in Fig. 5 (right). As before it is seen that the calculated (black) and measured (light/dark gray) spectra are in very good agreement both regarding spectral features and transmission levels. Moreover, the measured spectra for the two output channels are essentially identical in accordance with the symmetry of the Y-splitter. In the range 1560$1585 \mathrm{~nm}$, zero loss $3 \mathrm{~dB}$ output is obtained from each channel of the Y-splitter. In the range 1370-1410 nm the excess loss is found to be in the range 1-2 dB. The low loss bandwidth may be further extended by optimization of the Y-junction and the bends of the splitter employing additional repeated 3D FDTD calculations.
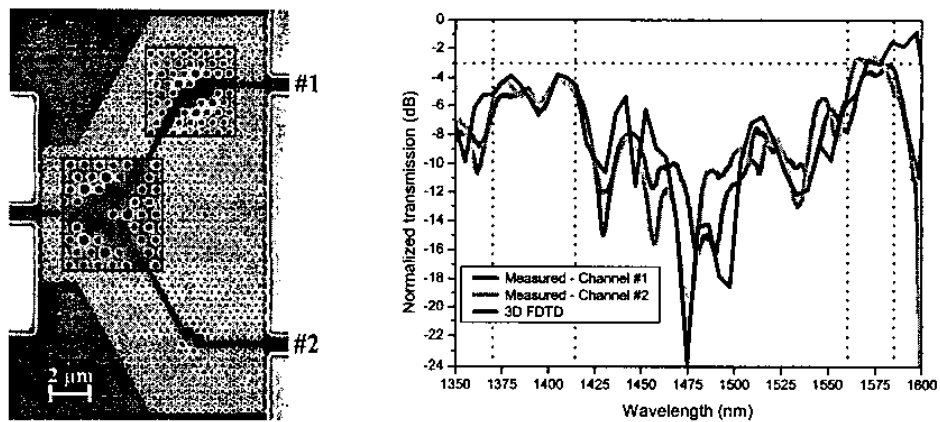

Figure 5. (Left): Scanning electron micrograph of the fabricated photonic crystal waveguide splitter. Insets show zoom-ins on the Y-junction and the $60^{\circ}$ bend. (Right): Measured spectra for TE-polarized light output (light/dark gray) of the fabricated PhC Y-splitter and calculated 3D FDTD spectrum (black).

\section{CONCLUSIONS}

In this paper we have shown that the functionality of a $\mathrm{PhCW}$ component may be considerably enhanced when using the appropriate design tools. We have presented examples of ultra-compact photonic crystal components realized in silicon-on-insulator material displaying high transmission features. This includes $60^{\circ}$ and $120^{\circ}$ bends and Y-splitters. The systematic inverse design method topology optimization have been found to allow the 
creation of improved $\mathrm{PhC}$ components with previously unseen low transmission losses and high operational bandwidths. The topology optimized $\mathrm{PhCW}$ structures can readily implemented into SOI material by the use of e-beam lithography. However, due to the subtleness of the shape and size of the topology optimized holes, it may in some cases be challenging to implement such PhCW structures when deep UV lithography is employed. . Moreover, we have shown that high operational bandwidths also can be obtained by use of systematic repeated 3D FDTD calculations. The PhCW components can readily be designed with sufficient tolerances for fabrication with standard deep UV lithography.

\section{ACKNOWLEDGEMENTS}

The authors acknowledge P. Shi of the Department of Micro and Nanotechnology at Technical University of Denmark for assistance with the e-beam lithography and W. Bogaerts, Roel Baets, and coworkers of IMEC at Ghent University, Belgium, for performing the deep UV lithography.

\section{REFERENCES}

[1] E. Yablonovitch: Inhibited spontaneous emission in solid-state physics and electronics, Phys. Rev. Lett. 58, 2059-2062 (1987).

[2] S. John: Strong localization of photons in certain disordered dielectric superlattices, Phys. Rev. Lett. 58, 2486-2489 (1987).

[3] T. F. Krauss, R. M. De La Rue, and S. Brand: Two-dimensional photonic-bandgap structures operating at near-infrared wavelengths, Nature 383, 699-702 (1996).

[4] J. Arentoft, T. Søndergaard, M. Kristensen, A. Boltasseva, M. Thorhauge and L. Frandsen, "Low-loss silicon-on-insulator photonic crystal waveguides," Electron. Lett. 38, 274-275 (2002).

[5] P. I. Borel, L. H. Frandsen, M. Thorhauge, A. Harpøth, Y. X. Zhuang, M. Kristensen, and H. M. H. Chong: Efficient propagation of TM polarized light in photonic crystal components exhibiting band gaps for TE polarized light, Opt. Express 11, 1757-1762 (2003).

[6] S. J. McNab, N. Moll, and Y. A. Vlasov: Ultra-low loss photonic integrated circuit with membrane-type photonic crystal waveguides, Opt. Express 11, $2927-2939$ (2003).

[7] Y. Sugimoto, Y. Tanaka, N. Ikeda, Y. Nakamura, K. Asakawa, and K. Inoue: Low propagation loss of $0.76 \mathrm{~dB} / \mathrm{mm}$ in GaAs-based single-line-defect two-dimensional photonic crystal slab waveguides up to $1 \mathrm{~cm}$ in length, Opt. Express 12, 1090-1096 (2004).

[8] M. Notomi, A. Shinya, S. Mitsugi, E. Kuramochi, and H-Y. Ryu: Waveguides, resonators and their coupled elements in photonic crystal slabs, Opt. Express 12, 1551-1561 (2004).

[9] M. Thorhauge, L. H. Frandsen and P. I. Borel: Efficient Photonic Crystal Directional Couplers, Opt. Lett. 28, 1525-1527 (2003).

[10] L. H. Frandsen, P. I. Borel, Y. X. Zhuang, A. Harpøth, M. Thorhauge, M. Kristensen, W. Bogaerts, P. Dumon, R. Baets, V. Wiaux, J. Wouters, and S. Beckx: Ultra-low-loss 3-dB Photonic Crystal Waveguide Splitter, Opt. Lett. (to be published July 2004).

[11] D. Taillaert, H. Chong, P.I. Borel, L.H. Frandsen, R.M. De La Rue, and R. Baets: A Compact Twodimensional Grating Coupler used as a Polarization Splitter, IEEE Photon. Technol. Lett. 15, 1249-1251 (2003).

[12] A. Lavrinenko, P. I. Borel, L. H. Frandsen, M. Thorhauge, A. Harpøth, M. Kristensen, T. Niemi, and H. M. H. Chong : Comprehensive FDTD modelling of photonic crystal waveguide components, Opt. Express 12, 234-248 (2004).

[13] P. I. Borel, A. Harpøth, L. H. Frandsen, M. Kristensen, P. Shi, J. S. Jensen, and O. Sigmund: Topology optimization and fabrication of photonic crystal structures, Opt. Express 12, 1996-2001 (2004).

[14] M. P. Bendsøe and N. Kikuchi: Generating optimal topologies in structural design using a homogenization method, Comput. Meth. Appl. Mech. Engng. 71, 197-224 (1988).

[15] M. P. Bendsøe and O. Sigmund: Topology optimization - Theory, Methods and Applications, SpringerVerlag, 2003.

[16] T. Søndergaard, J. Arentoft and M. Kristensen: Theoretical analysis of finite-height semiconductor-oninsulator based planar photonic crystal waveguides, J. Lightwave Technol. 20, 1619-1626 (2002).

[17] M. Kristensen, L.H. Frandsen, A. Harpøth, Y.X. Zhuang, P.I. Borel, W. Bogaerts, P. Dumon, R. Baets, V. Wiaux, J. Wouters, S. Beckx: Large bandwidth $60^{\circ}$ bend in photonic crystal waveguides, Paper Tu-F5, PECS-V, Kyoto, Japan, March 7-11.2004. 